\title{
Modelo Hackefors para obtenção de certificado ambiental ISO- 14.001 em pequenas e médias empresas - uma discussão sobre sua aplicação em empresas brasileiras
}

José Jorge Abdalla*

Susana Arcangela Quacchia Feichas**

\begin{abstract}
Resumo
Baseado em estudo feito no Distrito Industrial Fazenda Botafogo, no município do Rio de Janeiro, este artigo analisa a possibilidade de aplicação conjunta em distritos industriais brasileiros de um modelo de sistema de gestão ambiental (SGA), o modelo Hackefors, criado para facilitar a obtenção da certificação ambiental ISO 14.001 por empresas de pequeno e médio porte de distritos industriais na Suécia. 0 modelo Hackefors, surgido em 1997 no distrito sueco que lhe deu o nome, foi adotado por 450 empresas de 24 distritos industriais daquele país, basicamente, por ter possibilitado a certificação ambiental a cada empresa que a ele aderiu, com ganhos individuais e coletivos para as mesmas.

Para a elaboração deste artigo, foi analisada a literatura sobre distritos industriais e sistemas de gestão ambiental e, também, consultados documentos relativos ao modelo Hackefors e ao Distrito Industrial Fazenda Botafogo. Além disso, foram entrevistados consultores que trabalharam na implantação do referido modelo, representantes das empresas do distrito industrial carioca e especialistas em certificação ISO 14.001. Esse esforço permitiu comparar as duas situações e fazer algumas considerações sobre a aplicação do modelo sueco em Fazenda Botafogo. 0 resultado mostra que as diferenças entre as situações iniciais de atuação ambiental nos dois distritos não são um empecilho à construção de redes. Revela ainda que as semelhanças existentes sugerem que a aplicação do modelo Hackefors no distrito industrial do Rio de Janeiro poderia ser bem-sucedida. Por outro lado, em Fazenda Botafogo não foi identificado nenhum fator que transformasse a busca individual por um sistema de gestão ambiental nos moldes da ISO 14.001 numa busca coletiva, como ocorreu nos distritos industriais suecos.
\end{abstract}

Palavras- chave: Cadma; certificação ambiental; distrito industrial; ISO-14.001; pequenas e médias empresas.

\begin{abstract}
This article describes a Swedish initiative for providing a joint ISO 14001 certification to small to medium-sized enterprises (SMEs). The model started in 1997 in the Hackefors industrial district - so named Hackefors model - is now used by 450 enterprises of a wide variety of different business in 24 other districts. In this study we examine the use of this successful experiment in a Brazilian industrial district, Fazenda Botafogo, in Rio de Janeiro that, at the same way than Hackefors, is composed by small to medium-sized enterprises.
\end{abstract}

Key words: Cadma; environmental certification; industrial district; ISO-14001; small-sized and medium-sized enterprises.

\footnotetext{
"Pesquisador/Propesquisa EBAPE. Mestre em Ciências da Administração. E-mail: jjorge@ fgv.br. Endereço: Praia de Botafogo, 190 - sala 1305.2 - CEP 22253900 Rio de Janeiro - RJ.

**Professora da EBAPE/FGV. Mestre em Ciência Ambiental pela UFF/PGCA e Bacharel em Administração Pública pela FGV/EBAPE . E-mail: quasar@ fgv.br. Endereço:

Praia de Botafogo, 190 - sala 1305.2 - CEP 22253900 Rio de Janeiro - RJ.
} 


\section{Introdução}

O modelo Hackefors mostra como pequenas e médias empresas da Suécia foram motivadas a adotar o sistema de gestão ambiental ISO 14.001 e a certificação correspondente, implantando um modelo baseado na ação coletiva. Os ganhos com essa ação conjunta nos chamaram a atenção e nos levaram a cogitar a aplicação desse modelo em empresas brasileiras do mesmo porte.

Iniciamos o trabalho cientes das diferenças em termos socioculturais e de histórico de desenvolvimento industrial entre os dois países. Contudo, Brasil e Suécia têm em comum a grande quantidade de pequenas empresas, justamente aquelas que têm dificuldade em priorizar ações ambientais, mas que precisam aperfeiçoar seus processos produtivos em prol do meio ambiente, tendo em vista o potencial poluidor que têm em seu conjunto.

Através de pesquisa bibliográfica, buscamos entender a formação dos distritos industriais e das redes, bem como o significado da implantação de um sistema de gestão ambiental (SGA) e a obtenção de certificado ambiental de conformidade em pequenas e médias empresas. A análise documental e as entrevistas deram embasamento não apenas à descrição do modelo Hackefors, mas também da situação do Distrito Industrial Fazenda Botafogo. A partir daí, foi possível comparar as duas realidades, identificar semelhanças e diferenças e especular sobre a aplicação do modelo nesse distrito.

Este estudo indaga sobre as possibilidades de aplicação do modelo sueco, tomando por base pesquisa feita no Distrito Industrial Fazenda Botafogo, no município do Rio de Janeiro. Esse distrito foi escolhido por ser formado de pequenas e médias empresas, pela existência de uma associação das empresas do distrito, pela instalação do Ecopolo ${ }^{1}$ e por ser de fácil acesso. Nesse sentido, deve ser observado que aqui não se pretende extrapolar os resultados deste estudo para a realidade das empresas brasileiras, já que a comparação feita já foi um desafio. Portanto, os resultados apresentados são preliminares e a expectativa é a de que levem a um pesquisa mais aprofundada naquele distrito, envolvendo as empresas nessa discussão.

\section{Base conceitual}

Adiante, serão apresentadas as definições e os conceitos aos quais se recorreu para comparar dados de países de histórico industrial tão diferentes.

\section{Distrito industrial e rede de empresas}

Na busca de uma conceituação para distrito industrial, nos deparamos com uma variedade de expressões, tais como "pólo industrial" e "centro industrial", entre outras. Neste estudo, recorremos ao conceito apresentado por Oliveira (1976, p.13). Para ele, distrito industrial é uma área industrial planejada, estreitamente vinculada a um núcleo urbano e dotada de infra-estrutura física e de serviços de apoio necessários à indução de um processo de desenvolvimento.

De acordo com Schmitz e Musyck (1994), os principais atributos dos distritos industriais seriam:

- a proximidade geográfica;

- a especialização setorial;

- a predominância de pequenas e médias empresas;

\footnotetext{
1 Ecopolo é a "reunião de empreendimentos de qualquer setor de atividade que assumem conjuntamente o compromisso com o desenvolvimento sustentável, e que aproveitam as sinergias para fazer a melhor gestão de subprodutos, resíduos, infra-estrutura e logística." (Paulo Coutinho, slide de apresentação do Ecopolo). O Programa Rio Ecopolo foi criado pelo Decreto estadual n.․ 31.339 de 04 de junho de 2002 e o Ecopolo do Distrito Industrial da Fazenda Botafogo instalado em setembro do mesmo ano.
} 
- a colaboração entre as empresas;

- a competição interna mais focada em inovação do que em preço;

- a identidade sociocultural, facilitando a relação de confiança entre as empresas e entre empregados e empregadores; e

- uma ação governamental que fortalece a capacidade de inovação da indústria local.

Segundo Oliveira (1976), os distritos industriais proliferaram em diferentes países, por iniciativa governamental, a partir de década de 1950. Seu objetivo era estimular o desenvolvimento industrial em outras áreas além das já tradicionais, seja pela realocação de empresas localizadas nos centros urbanos e que tivessem planos de se expandir e/ou pela implantação de outras empresas, levando dessa forma desenvolvimento a outras regiões do país. Para as empresas, a formação dos distritos é vantajosa por causa dos incentivos governamentais oferecidos e também pela possibilidade de rateio dos custos de infra-estrutura, tais como serviços bancários, de comunicação, energia e parqueamento, entre outros.

Quanto ao conceito de rede de empresas, este se refere, principalmente, a formatos organizacionais definidos a partir de um conjunto de articulações entre empresas, que podem estar presentes em quaisquer aglomerados produtivos. Esse conceito envolve a realização de transações e/ou o intercâmbio de informações e conhecimentos entre os agentes, não implicando necessariamente a proximidade espacial de seus integrantes (REDESIST, 2003). Assim, o distrito industrial pode ser comparado a um condomínio residencial, onde se compartilha a infra-estrutura, sem que necessariamente haja maior interação entre as empresas ali situadas. Já, a rede de empresas se caracteriza pela interação entre as empresas, facilitada pela tecnologia da informação, e que tem como objetivo realizar ações conjuntas que propiciem ganhos a todos os participantes.

\section{M eio ambiente e sistema de gestão ambiental}

Para contextualizar o tema "gestão ambiental", tomamos a Conferência de Estocolmo (Suécia), realizada em 1972, como um marco da dimensão global que as questões relativas ao meio ambiente passaram a ter. Patrocinada pela ONU, foi a primeira conferência a propor discussões sobre meio ambiente e desenvolvimento. Nessa reunião, foi lançado um alerta para a poluição causada pelo modelo de desenvolvimento em curso industrialização, urbanização, mecanização da agricultura e uso de agrotóxicos - e para a finitude dos recursos naturais (MEADOWS, 1972).

Desse encontro surgiu o conceito de ecodesenvolvimento para definir uma estratégia de desenvolvimento fundamentada na utilização racional dos recursos locais. A Conferência de Estocolmo é, até hoje, um marco na história das Nações Unidas e na agenda política internacional, pelo impacto que causou na opinião pública internacional e pelos resultados alcançados nos diversos países, como, por exemplo, a criação de agências, secretarias e ministérios do meio ambiente. A partir daí, em espaços de tempo e em graus diferentes, o meio ambiente passa a ser incorporado à agenda de políticas públicas - através de medidas regulatórias - e ao processo decisório das organizações produtivas de países dos diferentes continentes.

De um ponto de vista que colocava em campos opostos "desenvolvimento" e "meio ambiente", nos últimos 30 anos se caminhou para uma visão de desenvolvimento sustentável, que busca traduzir uma preocupação de longo prazo e compatibilizar crescimento econômico com sustentabilidade ambiental e eqüidade social. Harrington e Knight (2001, p.29), identificam nesse processo seis estratégias através das quais as organizações administram as questões ambientais, e que podem ser interpretadas como etapas a serem vencidas na direção do desenvolvimento sustentável. Tais estratégias administrativas seriam:

1. baseada em artifícios: diante de uma pressão regulatória, a empresa fecha as portas em busca de uma local com menos exigências;

2. baseada em respostas: responde a incidentes e regulamentações ambientais, conforme tenha informações a respeito; 
3. baseada em conformidade: identifica sistematicamente os requisitos reguladores e adota medidas, controla riscos, cumpre a lei, o custo ambiental é planejado e pode ou não ser uma vantagem competitiva;

4. gestão ambiental: gerencia sistematicamente suas questões ambientais. Identifica aspectos e impactos, desenvolve políticas, objetivos e metas, aloca recursos e avalia desempenho;

5. prevenção de poluição: melhorias em seus processos e produtos para minimizar o impacto ambiental, racionalizar o uso de recursos naturais e diminuir resíduos e efluentes;

6. desenvolvimento sustentável: a empresa avalia os impactos social, ambiental e econômico causado por suas atividades, produtos e serviços. A gestão visa à responsabilidade social, moral e ética.

Conforme o exposto, percebe-se que as estratégias um e dois identificam uma postura defensiva e reativa das empresas. As estratégias três a seis mostram uma atitude empresarial voltada para a sistematização das decisões e ações relativas ao meio ambiente e um compromisso de longo prazo. A estratégia seis vai além, ao aplicar algum sistema de gestão ambiental (SGA) e estabelecer um compromisso entre a empresa e o seu entorno.

Segundo Barbieri (2004), o SGA é o conjunto de atividades administrativas e operacionais inter-relacionadas que abordam ou evitam os problemas ambientais atuais. Cada empresa pode criar o seu próprio sistema ou adotar um dos modelos propostos por outras entidades nacionais ou internacionais, posicionando-se assim em qualquer dos níveis de estratégia acima de três.

As normas da série ISO 14.000, desenvolvidas por especialistas de diferentes países e reconhecidas mundialmente, embora de caráter voluntário, têm sido adotadas por várias empresas, com maior aceitação nos países da União Européia, segundo Harrington e Knight (2001). Até 31 de dezembro de 1999, foram concedidas 14.106 certificações ISO 14.001, 53\% na Europa, 31\% no Oriente, $7 \%$ na América do Norte, 5\% na Austrália e Nova Zelândia, $2 \%$ na América do Sul e Central e $2 \%$ na África e Ásia Ocidental. No Brasil, o número de certificações era de 165 (REVISTA MEIO AMBIENTE INDUSTRIAL, 2000, p.28-29). Em 2004, eram contabilizadas 1.500 empresas no país, certificadas conforme a ISO 14.001, o que mostra o crescente interesse por essa certificação (REVISTA MEIO AMBIENTE INDUSTRIAL, 2004).

A ISO 14.001/SGA - Especificações e Diretrizes para Uso, que normatiza a implantação de um sistema de gestão ambiental, indica em seu texto que pode ser aplicada em qualquer tipo de organização, não importando sua complexidade, atividade ou tamanho. Sua implantação pode ser gradual, numa unidade operacional ou numa atividade específica, e se caracteriza por definir "o que" deve ser feito e não "como" deve ser feito. A aplicação da norma dá flexibilidade à organização e estabelece um processo de melhoria contínua da gestão. A previsão de auditorias externas independentes é outro fator que aumenta a credibilidade no sistema e possibilita conseguir a certificação.

Apesar da certificação ambiental ISO 14.001 não ser obrigatória para que seja implantado um SGA, segundo Maimon (1999), Harrington e Knight (2001) e outros autores, o certificado possibilita:

- o atendimento à regulamentação governamental e aos requisitos dos clientes, acionistas e outros stakeholders;

- a médio e longo prazo, a obtenção de vantagem competitiva para as empresas, principalmente aquelas voltadas para o mercado externo;

- a indução de melhorias no sistema de gestão como um todo; e

- a redução do custo de visita de clientes ao empreendimento, tendo em vista a credibilidade da certificação.

A implantação de um sistema de gestão ambiental deve ser vista como a vontade de uma empresa de tomar iniciativas sistematizadas e de longo prazo voltadas para o planejamento, a organização e o controle dos seus 
processos produtivos focando a questão ambiental. A iniciativa visa um aproveitamento mais eficiente dos recursos naturais, procurando minimizar impactos ambientais negativos, além de prevenir, recuperar e conservar o meio ambiente.

Os maiores obstáculos na busca por essa certificação têm sido o custo direto com o atendimento às auditorias, o custo indireto de envolvimento de funcionários da empresa nesse processo e os investimentos para alcançar a conformidade ambiental. Entretanto, essa análise, considera apenas os desembolsos, não levando em conta o retorno do investimento de médio e longo prazos, como ocorre nas empresas que já tiveram tempo para avaliar os resultados da implantação desse sistema.

No caso específico das pequenas e médias empresas, Maimon (1999) aponta, ainda, como barreiras à implantação do SGA- ISO 14.001:

- a preocupação em gerenciar o fluxo de caixa para chegar ao final do mês, além do custo de um financiamento;

- a centralização de decisões e a falta de visão de longo prazo;

- a ausência de dados e informações sobre a empresa e de acesso à informação;

- a defasagem tecnológica;

- dispor de mão-de-obra enxuta, pouco qualificada, sujeita à rotatividade, o que cria obstáculos à implantação de treinamento e torna difícil conseguir o comprometimento dos empregados, um dos requisitos dessa norma.

Levando em conta a importância de melhorar a performance ambiental das pequenas e médias empresas devido ao seu impacto coletivo no meio ambiente, Hillary (2000) entende que implantar um sistema de gestão ambiental é uma forma de conseguir essa melhora.

\section{0 modelo Hackefors}

Na Suécia, a solução encontrada para os problemas relacionados com a performance ambiental das pequenas e médias empresas ${ }^{2}$ foi a colaboração através de redes para conseguir a certificação conjunta ISO 14.001. Um exemplo disso foi a criação de um modelo a partir da experiência do distrito industrial de Hackefors.

Estudos sobre esse modelo revelam que uma forma das pequenas e médias empresas se tornarem mais competitivas é pela colaboração em redes, articulando ações conjuntas. A colaboração formal, através de redes, tem efetivamente ajudado essas empresas em diversas áreas, sendo empregadas no desenvolvimento de produtos, no marketing, na pesquisa, na obtenção das certificações ISO 9.000 e ISO 14.001, bem como no turismo e na solução de questões relacionadas à sustentabilidade (HALME et al, 2000; AMMENBERG et al, 1999; HENRIKSEN, 1995).

São evidentes os benefícios que a colaboração em rede proporciona às pequenas e médias empresas, como o acesso à informação e ao conhecimento, a inputs especializados e a infra-estrutura. Em termos de gestão ambiental, tais benefícios podem ser de grande importância para essas empresas, permitindo-lhes obter recursos e serviços a custos mais razoáveis, através de iniciativas como compras comuns e educação e treinamento (HUMAN e PROVAN, 1997).

\footnotetext{
${ }^{2}$ A Commision of European Communities (2001) classifica como pequenas empresas aquelas que empregam de 10 a 49 pessoas e médias as que empregam de 50 a 249 pessoas.
} 
Hackefors é um distrito industrial na Suécia, localizado na cidade de Linköping. Reúne cerca de 90 pequenas e médias empresas distribuídas em setores diversos, empregando aproximadamente 1.500 pessoas. Cerca de metade dessas empresas tem menos de 8 empregados e a maior delas emprega 70 pessoas.

Das empresas existentes nesse distrito, 26, através de uma rede, implementaram um sistema de gestão ambiental conjunto, com a finalidade de conseguir o certificado ISO 14.001. Essas empresas atuam nos mais diversos segmentos, como o de reciclagem de resíduos, transporte, construção, fabricação, comércio e indústrias gráficas, entre outros.

A rede de empresas surgiu em 1995, para impedir o fechamento do posto dos correios de Hackefors. Depois disso, continuou a atuar em diversas áreas, como informação, postagem e, mais tarde, meio ambiente. De forma sistemática, o trabalho ambiental começou em 1996, quando foi feito um inventário de resíduos gerados em todas as 90 companhias. No ano seguinte, foi criada uma unidade central para coleta, separação e utilização desses resíduos. Essa colaboração ampliou a consciência ambiental e, a partir daí, algumas empresas decidiram estabelecer um perfil ambiental para o distrito. Ainda em 1997, foram iniciados contatos e discussões com organizações ambientais para implementar um sistema de gestão ambiental. Como resultado, 26 companhias formaram o Grupo Ambiental Hackefors e começaram a desenvolver um SGA conjunto. Em 1999, todas as empresas do grupo, individualmente, já haviam recebido a certificação ISO 14.001. O modelo utilizado inicialmente em Hackefors, e que lhe deu o nome, é empregado hoje em 24 distritos industriais da Suécia, envolvendo 450 companhias (AMMENBERG e HJELM, 2002 apud HALLINAN, P.; JENKS, R, 2004).

A figura 1 mostra a estrutura do SGA implantado pelo Grupo Ambiental Hackefors

\section{Figura 1 - Estrutura do SGA de Hackefors}

\section{COORDENADOR CENTRAL}

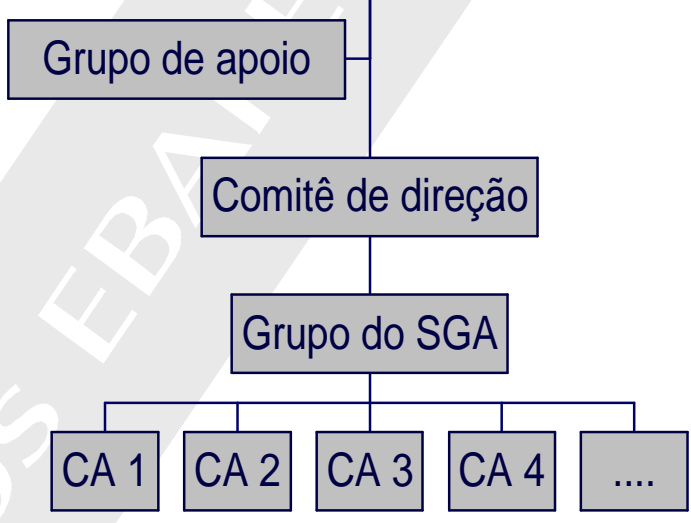

Fonte: Elaborado a partir de Hallinan e Jenks (2004)

Cada uma das companhias que participam do grupo ambiental no modelo Hackefors possuem um coordenador ambiental (CA1, CA2,....). Juntos, formam o grupo do sistema de gestão ambiental. A partir desse grupo é constituído um comitê de direção, composto por sete coordenadores escolhidos por seus pares. O comitê, por sua vez, escolhe um coordenador central que supervisiona os trabalhos do grupo do SGA. O coordenador central e o comitê de direção são ajudados na execução de suas tarefas por um grupo de apoio formado por empregados das companhias participantes.

O sistema conjunto é organizado de maneira semelhante ao de uma grande empresa. Nele, o comitê de direção, o grupo de apoio e o coordenador central, juntos, podem ser comparados ao staff ambiental da grande empresa. 
Por sua vez, o grupo do sistema de gestão ambiental, constituído dos coordenadores ambientais, exerce as funções operacionais para implantação do sistema. No modelo em questão, o coordenador central pode vir de uma companhia pertencente ou não ao grupo ambiental. No caso do Hackefors original, o coordenador central era de uma companhia de consultoria do grupo ambiental daquele distrito. O pessoal dessa consultoria assessorava o coordenador, o comitê de direção e também os coordenadores ambientais, através de relatórios, documentação e treinamento.

Na implantação do SGA conjunto, tendo como referência os requisitos da norma ISO 14.001, a política, a definição de objetivos ambientais, os documentos e as rotinas comuns foram tratados de forma coletiva; estabelecendo, portanto, uma política única para as empresas do grupo ambiental. Os outros requisitos da norma tiveram caráter individual, isto é, por empresa, como identificação de aspectos e impactos, requisitos legais, programa de gestão ambiental, estrutura e responsabilidade, comunicação, controles, monitoramento, registros e auditorias.

Ao recorrerem ao modelo Hackefors para investigar a colaboração de pequenas e médias empresas através de redes como uma possível maneira de ampliar as atividades ambientais, Hallinam e Jenks (2004) identificaram quatro diferentes e relevantes fatores que pressionaram essas empresas a procurarem ter a certificação ISO 14.001: a pressão dos clientes, as leis e regulações, os competidores que já possuem essa certificação e os fornecedores.

De acordo com o estudo, quem mais exerceu pressão sobre as empresas foram os clientes. Nos últimos anos, os clientes passaram a ter uma maior consciência sobre as questões relacionadas ao meio ambiente e conseqüentemente a exercer uma maior demanda nesse sentido. Passaram então a pressionar as empresas a obterem a certificação ISO 14.001, como uma demonstração da preocupação das organizações com as questões ambientais. Quanto aos motivos alegados pelas empresas para adotarem a certificação, o principal foi a melhoria da imagem, seguido da melhoria das relações com os clientes e a busca de nova clientela. As outras razões apresentadas foram a diminuição do impacto ambiental e a melhora das relações com os outros integrantes da rede.

Para as empresas, a maior vantagem do processo de certificação em grupo foi, sem dúvida, a redução dos custos de certificação, que saiu pela metade do que seria pago pela certificação individual; devendo ser ressaltado ainda que cada uma delas recebeu seu certificado próprio. Além disso, foram observadas melhorias nas questões administrativas e na educação relacionada à certificação. Depois de obtida a certificação, as empresas passaram a colaborar também em outras áreas, principalmente na divisão dos gastos com marketing e propaganda, troca de produtos e serviços e treinamento de pessoal.

Considerando que dois terços das companhias não cogitavam implementar um sistema de gestão ambiental antes do modelo Hackefors, é razoável supor que este é um fator de motivação para as pequenas e médias empresas em relação ao tema.

\section{Distrito Industrial Fazenda Botafogo}

Na cidade do Rio de Janeiro, os distritos industriais se desenvolveram na década de 1970, como forma de ordenar o zoneamento da cidade e estimular a implantação de indústrias. O Distrito Industrial Fazenda Botafogo é um exemplo. Naquela época, foi visto como uma iniciativa pioneira pela integração habitação/indústria, visando ao desenvolvimento socioeconômico da região. 
Em setembro de 2004, o distrito reunia 33 empresas, em sua maioria de pequeno e médio porte, segundo a Lei $\mathrm{n}^{\mathrm{o}}$ 9.841/99. ${ }^{3}$ Cabe destacar que na pesquisa de campo não foi possível identificar todas as empresas lá instaladas, razão pela qual nos limitamos às 24 indústrias vinculadas à Associação das Indústrias do Distrito Industrial da Fazenda Botafogo (Asdin), criada em 1978.

A adesão à associação é voluntária. A função da entidade é fazer a interface das empresas com as autoridades competentes, municipais e estaduais, e com a comunidade local, atendendo às necessidades das empresas associadas, coletivamente ou caso a caso.

\section{Gráfico 1 - Porte das empresas associadas à ASDIN}

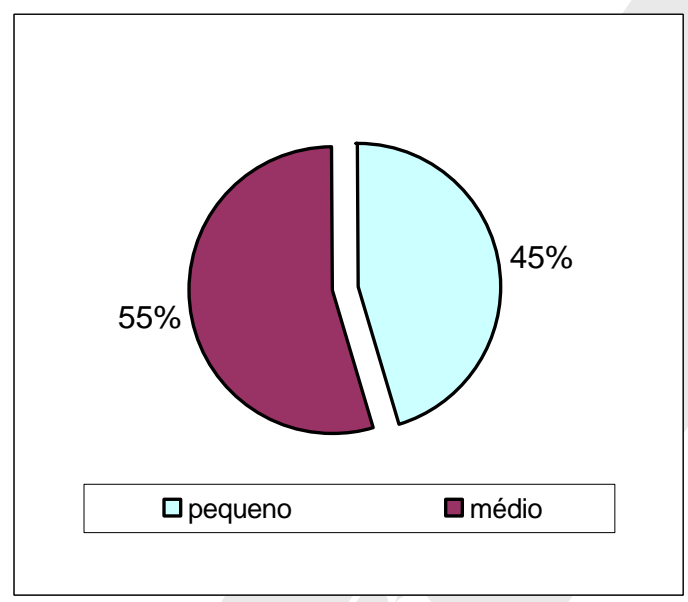

Fonte: Asdin e Firjan (2003, 2004).

Das 24 empresas associadas à Asdin, identificamos nove de pequeno porte (20 a 99 pessoas ocupadas) e 11 de médio porte (de 100 a 499 empregados), totalizando aproximadamente 2.900 empregados, ${ }^{4}$ dos quais 465 trabalhando em empresas de pequeno porte e 2.435 nas de médio porte. Essas empresas atuam em diversos ramos da indústria, como os setores químico, metalúrgico, de vidro, de máquinas e equipamentos, de plástico e de material de limpeza.

A atuação da Asdin se destaca pela apoio que a entidade presta aos seus associados nas áreas jurídica, fiscal e de recursos humanos, através de dois grupos de trabalho específicos. Esses grupos se reúnem uma vez por mês, separadamente, para discutir pontos polêmicos da legislação, referentes a cada matéria, procurando cada um adotar um postura o mais próxima possível da do outro, o que tem facilitado os entendimentos com os órgãos governamentais. A integração da área de recursos humanos das empresas associadas possibilitou, por exemplo, a criação do Serviço de Engenharia, Segurança e Medicina do Trabalho Coletivo (SESMTC) que, através de convênio com o Ministério do Trabalho, trata de forma coletiva das questões relativas a essa área. Por conta dessa iniciativa foi contratado um único prestador de serviço, com ganhos para as empresas que ratearam os custos fixos.

\footnotetext{
${ }^{3}$ Segundo o Estatuto da Microempresa e da Empresa de Pequeno Porte (BRASIL, 2000) o porte das empresas é definido por sua receita bruta anual ou pelo número de pessoas que empregam. Neste estudo, foi adotado esse último critério em virtude do acesso mais fácil a essa informação e pela sua comparabilidade com o parâmetro adotado pela União Européia. A Lei nº $9.841 / 99$ considera microempresas aquelas que empregam até 19 pessoas, pequenas empresas as que mantém de 20 a 99 pessoas ocupadas, médias empresas as que têm entre 100 e 499 empregados e grandes empresas, as que tenham mais de 500 funcionários.
}

\footnotetext{
${ }^{4}$ Até o momento da apresentação deste artigo, não obtivemos dados sobre o número de empregados de quatro empresas.
} 
$\mathrm{Na}$ área ambiental, por iniciativa da Fundação Estadual de Engenharia do Meio Ambiente (Feema), em junho de 2002, foi instituído o Programa Rio Ecopolo para oferecer incentivos fiscais às empresas que investirem em produção mais limpa, em reciclagem, na transformação de resíduos em matérias-primas e no reaproveitamento de água. Trata-se de um programa voluntário que, com assistência governamental, trabalha com associações de empresas de qualquer ramo, que buscam a excelência ambiental. Ainda em 2002, foi assinado um protocolo de intenções entre a Asdin e a Feema, chamado Rio Ecopolo da Asdin, cuja finalidade era implantar o Projeto Rio Ecopolo no Distrito Industrial da Fazenda Botafogo e em áreas industriais adjacentes. As 13 empresas que aderiram ao protocolo se reúnem periodicamente e têm dado continuidade às idéias do Ecopolo, conseguindo a adesão de outras empresas, independentemente de apoio governamental.

Além de discutir questões relativas ao cumprimento da legislação ambiental, as empresas do Ecopolo criaram dois grupos de trabalho: a subcomissão de resíduos e a subcomissão responsável pela formulação do Plano de Ação Integrada (PAI) para atender emergências. As reuniões das empresas que constituem o Ecopolo têm possibilitado, discutir e entender a legislação, além de elaborar ações conjuntas como disseminar informação o treinamento da brigada de incêndio, a programação de palestras na Semana do Meio Ambiente, a utilização de resíduos de uma empresa como matéria-prima de outra e a implantação de coleta seletiva. $O$ grupo está preparando um regimento interno e arrecadando recursos para criar um fundo que garanta a elaboração de um plano de gestão ambiental conjunto.

Pesquisa realizada nas empresas vinculadas à Asdin mostra que duas empresas de médio porte implantaram sistema de gestão ambiental próprio e que sete estão implantando algum sistema do gênero. Dessas sete, apenas duas são de pequeno porte. A certificação ambiental ISO 14.001 não é almejada pela maioria dessas empresas como algo para o futuro. Em cinco delas não há qualquer sistema de gestão ambiental. Cabe registrar que não foi possível contactar ou ter informação sobre 10 empresas.

\section{Análise comparativa: modelo "Hackefors" versus Distrito Industrial Fazenda Botafogo}

Destacamos diferenças e semelhanças entre o modelo Hackefors adotado em distritos industriais da Suécia e a realidade do Distrito Industrial da Fazenda Botafogo.

A Suécia, desde 1970, é caracterizada por uma gestão participativa nas empresas e por uma parceria entre os diferentes atores sociais (AKTOUF, 1996). É o caso da Volvo, empresa sujeita à competitividade, que conta com mão-de-obra qualificada e que garante benefícios sociais; diferentemente do que ocorre no Brasil, marcado pela acentuada desigualdade social, pela incipiente gestão participativa na maioria das empresas e por tentativas esparsas de constituição de parcerias entre empresas e destas com o poder público e a sociedade civil organizada.

Enquanto na sociedade sueca, convivem capitalismo e eqüidade social, no Brasil se convive com crescimento do PIB e a quarta pior distribuição de renda no mundo. Na Suécia, há um nível de confiança nas instituições que propicia a participação e a cooperação, essenciais para as parcerias e o trabalho em redes. No Brasil, esse processo de parcerias e redes está em construção.

Em diferentes graus, os dois países sofreram o impacto da recessão econômica mundial dos anos 1980 e da globalização na década de 1990. No Brasil, o quadro foi mais grave, levando em conta as taxas de inflação e o endividamento externo e interno, o que restringiu os investimentos públicos e privados, principalmente por parte das pequenas e médias empresas.

Contudo, o maior nível de participação, de parceria e cooperação, bem como a maior capacidade de investimento das empresas e a maior consciência ambiental da sociedade sueca não devem ser vistos como um empecilho à construção de redes de empresas no Brasil. Devem, sim, serem vistos como possibilidades a serem consideradas, respeitando-se as diferenças entre os dois países. 
No momento atual, destacamos outra diferença entre os dois países: as empresas suecas em questão optaram pela implantação de um sistema de gestão ambiental nos moldes da ISO 14.001, certificado que acabaram obtendo; enquanto as empresas da Fazenda Botafogo fazem opções diferentes em relação às questões ambientais.

Com base nas estratégias administrativas das organizações que investem no desenvolvimento sustentável, descritas por Harrington e Knight (2001, p.29), podemos afirmar que a decisão das empresas dos grupos ambientais do modelo Hackefors revela uma procura pela sistematização na abordagem das questões ambientais, enquadrando-se nos estágios acima de três. No caso das empresas da Fazenda Botafogo, observamos que algumas delas, todavia, assumem estratégias reativas, respondendo a incidentes e à legislação, atitudes que são próprias dos estágios um e dois. Outras estão no mesmo estágio que o das suecas, que é o da busca de algum sistema de gestão ambiental.

A posição das empresas do Distrito Industrial da Fazenda Botafogo nos estágios inferiores da escala anteriormente mencionada revela que apesar da legislação brasileira enfatizar a responsabilidade de todo cidadão pela proteção e preservação do meio ambiente, e a certificação ambiental ser apontada como relevante pela sua aceitação mundial, o número de empresas certificadas pela ISO14.001 no Brasil é pequeno se considerado o universo de empresas da economia brasileira.

Em maio de 2004, conforme anunciado na Revista Meio Ambiente Industrial, a certificação ISO 14.001 era uma realidade em apenas 1.500 empresas brasileiras. Mesmo levando em conta as empresas que adotam sistemas de gestão ambiental diferentes do ISO 14.001, podemos afirmar que, no universo das de pequeno e médio porte, no Brasil a maioria tem tido uma atitude reativa com relação ao meio ambiente, motivadas por pressões legais, diferentemente do proposto por um sistema de gestão ambiental.

Pelas entrevistas, realizadas em setembro de 2004, notamos que naquele momento a maioria das empresas do Distrito Industrial Fazenda Botafogo associadas à Asdin não pretendiam conseguir certificação ambiental. Entretanto, cabe lembrar que antes do modelo Hackefors ser aplicado, dois terços das companhias dos distritos suecos também não cogitavam da implementação de um sistema de gestão ambiental e de certificação, daí, ser razoável supor que o modelo é um fator de motivação para as pequenas e médias empresas.

Quanto à implantação conjunta de um SGA-ISO 14.001 no Distrito Industrial Fazenda Botafogo, aparentemente não existe uma pressão suficientemente forte por parte dos stakeholders para que isso ocorra a curto prazo. No entanto, mantida a atuação das empresas no Ecopolo, acreditamos na ampliação das ações conjuntas. O fato de nove empresas do Distrito Industrial Fazenda Botafogo estarem implantando ou já terem implantado um sistema de gestão ambiental deve ser visto como fator de motivação para as demais empresas participantes do Ecopolo. Outra diferença, diz respeito à motivação para que se busque conjuntamente implantar esse sistema. A pressão dos clientes ocorrida no caso das empresas suecas não foi verificada no caso das pequenas e médias empresas do distrito industrial carioca. As semelhanças entre os dois contextos se restringem à formação dos grupos e ao start das ações voltadas para gestão de resíduos.

Comparando a formação do grupo ambiental Hackefors com a da Associação das Indústrias do Distrito Industrial da Fazenda Botafogo percebe-se que, num primeiro momento, a iniciativa pela associação entre empresas estava centrada na defesa de interesses comuns: evitar o fechamento do posto do correio, no primeiro caso, e mediar conflitos entre as empresas, o Estado e a comunidade, no segundo. Da mesma forma, impulsionados pela maior competitividade no mundo empresarial, em ambos os casos, foram estabelecidas redes de cooperação e parceria, como as iniciativas do grupo de empresas em Hackefors e a criação do Serviço de Engenharia, Segurança e Medicina do Trabalho Coletivo (SESMTC), no âmbito da Asdin. Existem, ainda, semelhanças na constituição dos grupos ambientais Hackefors e do Ecopolo, como a participação de um representante de cada empresa participante e a escolha de um coordenador geral pelos seus pares. 
O Ecopolo da Fazenda Botafogo é um embrião do que pode se tornar uma rede semelhante aos grupos ambientais do modelo Hackefors, entre outros motivos, por ter sido implantado visando à parceria entre empresas, pelo envolvimento de representantes de cada empresa com atuação em qualidade, meio ambiente, segurança e saúde ocupacional, além de estar promovendo atividades que trazem ganhos financeiros aos envolvidos. Outra semelhança é que tanto no grupo original do modelo Hackefors como no Ecopolo, a mobilização inicial das empresas com relação a meio ambiente foi para cuidar da disposição dos resíduos sólidos, evoluindo no caso da Suécia para a implantação de um sistema de gestão ambiental conjunto, que propiciou a certificação ISO 14.001 individual. No caso do Ecopolo, a concepção desse programa - voltada para a produção mais limpa, cuja metodologia possibilita a redução de resíduos, a reciclagem e o reaproveitamento - pode indicar a opção do grupo da Fazenda Botafogo por priorizar ações de gestão de resíduos.

Os ganhos reais com o reaproveitamento de resíduos também pode ter levado a essa escolha. Numa das entrevistas nos foi relatado que a empresa vendia um determinado resíduo à outra empresa, em São Paulo - que o aproveitava como matéria-prima -, ficando sujeita ao preço ditado pela compradora e tendo de arcar com o custo de transporte. Nas reuniões do Ecopolo, a empresa produtora do resíduo descobriu que podia vendê-lo a uma empresa vizinha, maximizando ganhos para ambas. No momento da entrevista, ${ }^{5}$ essas empresas estavam em negociação.

Outra iniciativa constatada no Ecopolo foi a implantação de coleta seletiva por uma das empresas visitadas, sem contar outros processos similares em andamento. Por se estar lidando com resíduos sólidos, talvez essa opção se deva ao fato de que, tanto na experiência piloto de Hackefors como do Ecopolo na Fazenda Botafogo, haja uma empresa de reciclagem instalada no distrito e que é membro do grupo.

Da descrição e análise das experiências brasileira e sueca podemos concluir que as diferenças não chegam a ser um obstáculo à formação de redes para a implantação de ações de gestão ambiental conjuntas no distrito da Fazenda Botafogo. Já as similitudes parecem constituir um incentivo ao trabalho em rede, com possibilidades de consolidação, levando em conta os ganhos obtidos pelos membros do Ecopolo e pelas empresas que representam.

\section{Considerações finais}

Apesar dos resultados deste estudo serem preliminares, visto que a pesquisa se limitou a um único distrito industrial e nem sempre teve êxito na obtenção de dados - além do que a experiência recente do Ecopolo não permite, no momento, avaliar resultados de ações empreendidas em conjunto -, consideramos que a constituição de redes pode viabilizar a implantação de um sistema de gestão ambiental nas empresas de pequeno e médio porte. Essa constatação é reforçada pela necessidade de que sejam ampliadas as ações de gestão ambiental em função do número de micro, pequenas e médias empresas e pelas vantagens já constatadas com o trabalho em rede.

Tomando como exemplo dados do estado do Rio de Janeiro referentes ao ano de 2001 (RIO DE JANEIRO, 2004) verifica-se que $90 \%$ das indústrias de transformação são empresas que têm de 1 a 49 empregados; portanto, micro e pequenas empresas, segundo os padrões europeu e brasileiro. Considerando o potencial poluidor coletivo dessas empresas, bem como o baixo investimento em equipamentos e treinamento, deve haver alguma forma de controle para minimizar a degradação ambiental, que não se restrinja à regulação e à fiscalização. Por outro lado, podemos supor que esteja ocorrendo um efeito dominó iniciado nas grandes empresas que já têm certificação ambiental, e que estariam exigindo o mesmo dos seus contratados, subcontratados e fornecedores, a maioria dos quais, empresas de pequeno e médio porte. Nesse sentido pode ser

\footnotetext{
${ }^{5}$ Entrevista feita em set. 2004. Conforme acordado durante a pesquisa, as empresas não seriam identificadas.
} 
citado o exemplo do Progefe, ${ }^{6}$ implantado pela unidade de Engenharia da Petrobrás. Esse programa tem como objetivo pré-qualificar os prestadores de serviços a serem contratados com base em cinco critérios:

- capacitação técnica;

- $\quad$ situação econômico-financeira;

- aspectos legais;

- meio ambiente, saúde e segurança ocupacional; e

- ética empresarial.

Cabe ressaltar que três dos cinco critérios estão diretamente relacionados com questões de cunho ambiental e social, a saber: cumprimento da legislação - incluindo a regulamentação ambiental -, programas de gestão ambiental e a responsabilidade social.

Outro fator externo que estimula a adoção de sistemas de gestão ambiental pelas empresas está relacionado ao papel conscientizador assumido por diferentes associações de classe e setoriais, bem como a divulgação de boas práticas e de números relativos à taxa de retorno financeiro do investimento realizado em programas na área ambiental e social. Os dados sobre retorno demonstram que, a médio e longo prazos, vale a pena investir em meio ambiente e responsabilidade social, pois, além do retorno do investimento há outros ganhos relacionados à imagem, valorização da marca e conquista de mercado.

Se por um lado a pressão por práticas ambientais tende a aumentar sobre um número crescente de empresas, não se pode ignorar as dificuldades - principalmente, financeiras - das pequenas e médias empresas para investirem na melhoria de processos cujo retorno não é claramente percebido por seus proprietários e que só ocorrerá a médio e longo prazo.

A formação de redes de empresas, por possibilitar a redução de custos - conforme revelado pelos participantes do Grupo Hackefors - pode despertar o interesse pela implantação de sistemas de gestão ambiental conjuntos por pequenas e médias empresas no Brasil, do mesmo modo como aconteceu na Suécia. Cabe lembrar que esse ganho já foi percebido pelas empresas do Distrito Industrial da Fazenda Botafogo quando foi implantado o serviço de atendimento médico conjunto (SESMTC).

Análises sobre as redes revelam que o sucesso econômico associado a arranjos de pequenas empresas tem sido atribuído à "eficiência coletiva" (SCHMITZ, 1995, 1997), um conceito suficientemente amplo para abarcar desde ganhos obtidos com o processo de aglomeração até benefícios conseguidos com a colaboração de agentes econômicos.

Por outro lado, estudos de Kennedy (1999) comprovam que ações coletivas permitem aos empresários locais enfrentarem mais efetivamente o desafio do controle da poluição. As pressões para o alcance de padrões internacionais em áreas como qualidade, meio ambiente, ética, segurança e trabalho conseguem respostas viáveis através de ações coletivas. Os mesmos estudos constatam que o simples cumprimento da legislação ambiental já traz ganhos à indústria, ao mesmo tempo em que permite alcançar objetivos ambientais.

Visto que a certificação ambiental ISO 14.001 foi a opção das empresas suecas, ouvimos consultores da área sobre os ganhos que as empresas brasileiras teriam se optassem por uma contratação, nos moldes do modelo analisado. Segundo esses profissionais, de modo geral, os ganhos viriam do treinamento, da visita dos auditores e de ações de conformidade. Por sua vez, o ganho principal viria com o treinamento conjunto de empregados de diferentes empresas, pois o custo fixo seria repartido entre as empresas contratantes, levando-se em conta que quanto menor o porte da empresa, maior seria o seu ganho. Apesar dos custos com as auditorias de certificação

\footnotetext{
${ }^{6}$ Progefe. Gestão de fornecedores. Disponível em: <http://progefe.petrobras.com.br/progefe/default.cfm>.
} 
e do caráter individual das medidas de conformidade ambiental, a realização de visitas a diferentes empresas na mesma época permitiria ratear custos de deslocamento e hospedagem do consultor. Quanto aos investimentos necessários, somente após diagnóstico ambiental das empresas poderiam ser cogitadas ações conjuntas.

Em resumo, verificamos que conseguir uma certificação ambiental não é objetivo da maioria das empresas do Distrito Industrial da Fazenda Botafogo, ainda que estas venham implantando sistemas de gestão ambiental; o que pode servir de exemplo para as empresas que se limitam a ações ambientais pontuais. Além disso, é perceptível que fatores externos os mais diversos exercem pressão para que mais empresas atendam às exigências de natureza ambiental e social, para poderem se manter no mercado.

A formação de redes e de parcerias é um tema discutido em diferentes fóruns de discussão como nova possibilidade de gestão tanto para empresas, como governo e sociedade civil organizada. O Sebrae (Serviço Brasileiro de Apoio às Micro e Pequenas Empresas, ${ }^{7}$ por exemplo, estimula a parceria entre empresas de pequeno e médio porte na implantação de programas de responsabilidade social.

Por sua vez, a expansão das redes dependerá da disseminação de seus benefícios, como ocorreu na Suécia. Logo, aprofundar a pesquisa sobre os representantes das empresas do Ecopolo do Distrito Industrial da Fazenda Botafogo permitirá validar as especulações formuladas, como também acompanhar e avaliar os resultados.

A partir do que foi observado no Distrito Industrial da Fazenda Botafogo, verifica-se que são imprescindíveis para a criação e o funcionamento de uma rede:

- estabelecer um clima de confiança entre os atores;

- capacidade de implantar projetos que tragam ganhos reais para a empresa; e

- habilidade para estabelecer alianças internas e dar visibilidade aos ganhos dos projetos, como forma de "cooptar" a alta direção de cada empresa.

Podemos concluir que as redes são uma alternativa para promover a implantação de ações ambientais em empresas de pequeno e médio porte. Essa experiência pode reduzir custos, dar maior poder de negociação com os fornecedores, possibilitar a complementaridade de ações e ainda proporcionar um significativo aprendizado em termos de trabalho de parceria. Dessa forma, acreditamos que o modelo Hackefors poderia ser uma alternativa para as empresas brasileiras dispostas a trabalhar em rede, como no caso do Ecopolo.

\footnotetext{
7 "V Seminário de responsabilidade social: componente do modelo de desenvolvimento sustentável brasileiro", promovido pela Fundação Getulio Vargas (FGV) e o Sebrae, no Rio de Janeiro, em 15 abr. 2005.
} 


\section{Referências bibliográficas}

AKTOUF, O. Administração entre a tradição e a renovação. São Paulo: Atlas, 1996.

AMMENBERG et al. Joint EMS and group certification: a cost-effective route for SMES to achieve ISO 14001. Greener Management International, n.28, p.23-31, 1999.

BARBIERI, J.C. Gestão ambiental empresarial: conceitos, modelos e instrumentos. São Paulo: Saraiva, 2004.

BRASIL. Presidência da República. Estatuto da Microempresa e da Empresa de Pequeno Porte. Lei no $9.841 / 99$, regulamentada pelo Decreto no 3.474/00.

FIRJAN - Federação das Indústrias do Estado do Rio de Janeiro. Cadastro Industrial do Rio de Janeiro 2002. Rio de Janeiro: Firjan, 2003. . Cadastro industrial do Rio de Janeiro 2003. Rio de Janeiro: Firjan, 2004.

HALLINAN, P.; JENKS, R. The battle against environmental performance - the Hackefors model in Sweden. Thesis (Master) - International Business Programme, Linköpings Universitet. 2004.

HALME et al. Small and medium-sized enterprises in sustainable development networks. Greener Management International, n.30, p.97113,2000

HARRINGTON, H. J.; KNIGHT, A. A implementação da ISO 14.001: como atualizar o sistema de gestão ambiental com eficácia. São Paulo: Atlas, 2001.

HENRIKSEN, L. B. Formal cooperation among firms in networks: the case of Danish joint venture and strategic alliances. European Planning Studies, v.3, n.2,1995.

HILARY, R. Small and medium-sized enterprises and the environment - business imperatives. Sheffield: Greenleaf Publishing Limited, 2000.

HUMAN, S. E.; PROVAN, K.G. An emergent theory of structure and outcomes in small Firm strategic manufacturing networks. Academy of Management Journal, v.40, 1997.

KENNEDY, L. Cooperation for survival: tannery pollution and joint action in the Palar Valley (India). World Development, v.27, n.9, 1999, p.1673-1691.

MAIM ON, D. ISO 14.001: passo a passo da implantação nas pequenas e médias empresas. Rio de Janeiro: Qualitymark Editora, 1999.

MEADOWS, D. H. Limites do crescimento: um relatório para o projeto do Clube de Roma sobre o dilema da humanidade. São Paulo: Perspectiva, 1972.

OLIVEIRA, A. C. M. Distritos industriais: a experiência brasileira. Rio de Janeiro: CNI, 1976.

REDESIST. Glossário de arranjos e sistemas produtivos e inovativos locais. Disponível em: <www.ie.ufrj/redesist>. Acesso em: 2003.

REVISTA M EIO AM BIENTE INDUSTRIAL. São Paulo: Tocalino, n.25, p.28-29, jul./ago. 2000.

REVISTA M EIO AMBIENTE INDUSTRIAL. São Paulo: Tocalino, maio/jun. 2004. Edição especial.

RIO DE JANEIRO (Estado). Centro de Informações e Dados do Rio de Janeiro. Anuário estatístico do estado do Rio de Janeiro 2003. Rio de Janeiro: Cide, 2004. p.562.

SCHMITZ, H. Collective efficiency: growth path for small scale industry. Journal of Development Studies, v.31, n.4, p.529-566, 1995.

. Collective efficiency and increasing returns. Brighton: Institute of Development Studies, 1997. (Working paper, n. 50).

; MUSYCK, B. Industrial districts in Europe: police lessons for developing countries? World Development, v.22, n.6, p.889-910, 1994 